\title{
The Investigation of Strain-Induced Martensite Reverse Transformation in AISI 304 Austenitic Stainless Steel
}

\author{
G. CIOS, T. TOKARSKI, A. ŻYWCZAK, R. DZIURKA, M. STĘIEŃ, Ł. GONDEK, \\ M. MARCISZKO, B. PAWłOWSKI, K. WIECZERZAK, and P. BAłA
}

\begin{abstract}
This paper presents a comprehensive study on the strain-induced martensitic transformation and reversion transformation of the strain-induced martensite in AISI 304 stainless steel using a number of complementary techniques such as dilatometry, calorimetry, magnetometry, and in-situ X-ray diffraction, coupled with high-resolution microstructural transmission Kikuchi diffraction analysis. Tensile deformation was applied at temperatures between room temperature and $213 \mathrm{~K}\left(-60^{\circ} \mathrm{C}\right)$ in order to obtain a different volume fraction of strain-induced martensite (up to $\sim 70 \mathrm{pct}$ ). The volume fraction of the strain-induced martensite, measured by the magnetometric method, was correlated with the total elongation, hardness, and linear thermal expansion coefficient. The thermal expansion coefficient, as well as the hardness of the strain-induced martensitic phase was evaluated. The in-situ thermal treatment experiments showed unusual changes in the kinetics of the reverse transformation $\left(\alpha^{\prime} \rightarrow \gamma\right)$. The X-ray diffraction analysis revealed that the reverse transformation may be stress assisted - strains inherited from the martensitic transformation may increase its kinetics at the lower annealing temperature range. More importantly, the transmission Kikuchi diffraction measurements showed that the reverse transformation of the strain-induced martensite proceeds through a displacive, diffusionless mechanism, maintaining the Kurdjumov-Sachs crystallographic relationship between the martensite and the reverted austenite. This finding is in contradiction to the results reported by other researchers for a similar alloy composition.
\end{abstract}

DOI: $10.1007 / \mathrm{s} 11661-017-4228-1$

(C) The Author(s) 2017. This article is an open access publication

\section{INTRODUCTION}

THE formation of martensite during deformation is a very common phenomenon in austenitic stainless steels which, if susceptible to such transformations, are called metastable. The transformation from FCC (FaceCentered Cubic, $\gamma$ ) austenite to BCC (Body-Centered Cubic, $\alpha^{\prime}$ ) martensite may happen in a direct manner $\left(\gamma \rightarrow \alpha^{\prime}\right)$ which usually occurs on intersections of shear

G. CIOS, T. TOKARSKI, A. ŻYWCZAK, M. STEQPIEŃ, and M. MARCISZKO are with the Academic Centre for Materials and Nanotechnology, AGH University of Science and Technology, al. A. Mickiewicza 30, 30-059 Krakow, Poland. Contact e-mail: ciosu@ agh.edu.pl R. DZIURKA, B. PAWŁOWSKI, and K. WIECZERZAK are with the Faculty of Metals Engineering and Industrial Computer Science, al. A. Mickiewicza 30, 30-059 Krakow, Poland. $\longleftarrow$ GONDEK is with the Faculty of Physics and Applied Computer Science, al. A. Mickiewicza 30, 30-059 Krakow, Poland. P. BAŁA is with the Academic Centre for Materials and Nanotechnology, AGH University of Science and Technology, and also with the Faculty of Metals Engineering and Industrial Computer Science.

Manuscript submitted January 31, 2017.

Article published online July 18, 2017 bands, twins, or via HCP (Hexagonal Close Packed, $\varepsilon$ ) martensite $\left(\gamma \rightarrow \varepsilon \rightarrow \alpha^{\prime}\right) .{ }^{[1]}$ However, $\varepsilon$ martensite fully transforms into $\alpha^{\prime}$ when a higher strain is applied. The maximum volume fraction of $\varepsilon$ martensite is strongly dependent on the deformation temperature and usually takes place at strains lower than $0.15 .^{[2,3]}$ As reported by Tavares et al., ${ }^{[4]}$ it is possible to obtain a different transformation succession, i.e., $\gamma \rightarrow \alpha^{\prime} \rightarrow \varepsilon$ when applying high pressure, for instance by HPT (High Pressure Torsion) processing at the highest possible pressure and deformation conditions. The influence of BCC martensite and/or its formation on the materials properties such as mechanical, ${ }^{[5,6]}$ corrosion resistance,${ }^{[\uparrow, 8]}$ formability, ${ }^{[9-12]}$ hydrogen cracking susceptibility, ${ }^{[13-15]}$ and fracture propagation ${ }^{[16]}$ have been investigated. Mathematical models for strain-induced transformation in austenitic stainless steels have also been already developed. ${ }^{[17-19]}$

$\mathrm{BCC}$ as well as HCP martensite undergoes a reverse transformation during the heating process. Previous dilatometric studies revealed $\varepsilon \rightarrow \gamma$ reverse transformation between RT and $473 \mathrm{~K}\left(200{ }^{\circ} \mathrm{C}\right)$ and $\alpha^{\prime} \rightarrow \gamma$ reverse transformation in the range of $773 \mathrm{~K}$ to $1073 \mathrm{~K}\left(500{ }^{\circ} \mathrm{C}\right.$ 
to $\left.800{ }^{\circ} \mathrm{C}\right) .{ }^{[3,20]}$ Both $\left(\varepsilon \rightarrow \gamma, \alpha^{\prime} \rightarrow \gamma\right)$ transformations are shifted to higher temperatures with the increase of heating rate (at the heating rate higher than $0.1 \mathrm{~K} / \mathrm{s}$ ). ${ }^{[21]}$ Tomimura et al. described two types of possible reverse transformation $\left(\alpha^{\prime} \rightarrow \gamma\right)$ mechanisms: 1st diffusive by nucleation and growth of new austenite grains and 2nd diffusionless shear reversion. ${ }^{[2]}$ The reverse transformation plays a significant role in grain refinement in metastable austenitic stainless steels. UFG (U1trafine-grained) as well as NG (nano-grained) materials have been produced by reversion annealing of AISI 304, AISI 304L, and less stable AISI 301LN and AISI 201 metastable stainless steels, where the material strength is enhanced with a moderate decrease in plasticity. ${ }^{[23-29]}$ Grain refinement via reversion annealing still draws attention, i.e., Sun et al. ${ }^{[30]}$ reported diffusive reversion of strain-induced martensite during annealing in the range of $823 \mathrm{~K}$ to $923 \mathrm{~K}\left(550{ }^{\circ} \mathrm{C}\right.$ to $\left.650{ }^{\circ} \mathrm{C}\right) .{ }^{[30]}$

This paper reports the formation of SIM during the tensile test at different temperatures, and the reverse transformation analysis by the use of DSC, in-situ X-ray diffraction, and dilatometry. Moreover, to determine the reverse transformation sequence, samples were annealed at chosen temperatures and the resultant microstructure was investigated using a novel, high-resolution transmission Kikuchi diffraction technique. The main objective of this study was to gather more information about the influence of SIM formation on mechanical and physical properties and to find the SIM reverse transformation mechanism in the AISI 304 steel.

\section{EXPERIMENTAL}

The investigated material was an AISI 304 (1.4301, $\mathrm{X} 5 \mathrm{CrNi18-10)}$ stainless steel bar. For further investigations, the bar was cut into tensile samples $(\varphi 3 \times 110$ $\mathrm{mm})$ and solution heat treated from $1323 \mathrm{~K}\left(1050{ }^{\circ} \mathrm{C}\right)$ with soaking time of 1 hour in air. The oxide layer was removed by electropolishing in the Struers A2 solution.

The deformation was done using INSTRON 5982 universal testing machine equipped with a cooling chamber. Samples were tested in $296 \mathrm{~K}, 273 \mathrm{~K}, 263 \mathrm{~K}$, $253 \mathrm{~K}, 243 \mathrm{~K}, 223 \mathrm{~K}$, and $213 \mathrm{~K}\left(23{ }^{\circ} \mathrm{C}, 0{ }^{\circ} \mathrm{C},-10^{\circ} \mathrm{C}\right.$, $-20{ }^{\circ} \mathrm{C},-30{ }^{\circ} \mathrm{C},-50{ }^{\circ} \mathrm{C}$, and $-60{ }^{\circ} \mathrm{C}$ ) with the initial strain rate of $5.0 \times 10^{-4} \mathrm{~s}^{-1}$. Soaking time of $10 \mathrm{~min}$ utes was applied for temperature stabilization. All further investigations were performed on the uniform elongation zones of the deformed samples. Hardness measurements of fractured specimens (5 on each sample) were performed using Tukon 2500 by Wilson Hardness applying the Vickers method with the applied force of $9.8 \mathrm{~N}$ (HV 1). The uncertainty of mechanical properties was calculated based on the standard deviation.

Metallographic examination has been done on longitudinal sections of uniform plastic deformation zones of fractured specimens. The samples were ground, polished, and etched using $30 \mathrm{~g} \mathrm{NH}_{4} \mathrm{~F}+50 \mathrm{~mL} \mathrm{HNO}_{3}(65$ pct) $+20 \mathrm{~mL} \mathrm{H}_{2} \mathrm{O}$ reagent. The observation was carried out in bright-field and differential interference contrast (DIC) to reveal deformation features in samples.
Transmission Kikuchi diffraction (TKD) was used in order to investigate microstructure evolution during the reverse transformation. A standard technique was used for the preparation of the thin, electron transparent foil. Samples cut at a cross-section perpendicular to the tensile axis were mechanically ground and electropolished using A2 reagent in a Twin-jet polishing apparatus Tenu-pol-5 by Struers. TKD analysis was performed by means of scanning electron microscope Versa 3D by FEI equipped with Hikari EDAX camera and a custom-designed thin foil holder. Orientation and phase maps were collected at the $20 \mathrm{kV}$ of acceleration voltage, beam current of $16 \mathrm{nA}$, step size of $10 \mathrm{~nm}$, and acquisition rate of 100 to 200 patterns per second. The camera binning was set at $4 \times 4$ with the binned pattern resolution of $160 \times 120$ pixel. BCC (for strain-induced martensite) and FCC (for austenite) phases were chosen for phase analysis, where 8 bands on each Kikuchi pattern were analyzed. The average pixel fraction, with the confidence index higher than 0.1 , was at least 0.80 . More experimental details can be found in our previous paper. ${ }^{[31]}$ In order to avoid any image distortions, map cleaning/post-processing was not used.

A set of in-situ experiments, namely DSC, dilatometry, magnetometry, and X-ray, were used for the analysis of the reverse transformation mechanism during heating experiment. Details concerning the measuring conditions are presented in Table I.

In-situ magnetometric studies during heating and at room temperature were performed using vibrating sample magnetometer (VSM) 7407 by LakeShore. The applied magnetic field during room-temperature and heating experiments was equal $1 \mathrm{~T}$. Dilatometric investigations were carried out using the R.I.T.A. L78 induction heating high-resolution dilatometer by Linseis on $10-\mathrm{mm}$ cylindrical samples with the diameter in the range of $2.5 \mathrm{~mm}$ (diameter dependent on the elongation during the tensile test). The applied heating rate was $0.05^{\circ} \mathrm{C} / \mathrm{s}$ and the samples were heated up to $727 \mathrm{~K}$ $\left(1000^{\circ} \mathrm{C}\right)$. Differential scanning calorimetry measurements were carried out using the SDT Q600 by TA Instruments, where the sample purge gas was argon with the flow of $80 \mathrm{~mL} / \mathrm{min}$. X-ray diffraction (XRD) measurements for fractured specimens were performed by means of PANalytical's Empyrean diffractometer using Co $\mathrm{K}_{\alpha}(\lambda=1.7890 \AA)$ in the parallel beam (equipped with Goebel mirror) configuration. The X-ray tube operating parameters were $40 \mathrm{kV}$ and $40 \mathrm{~mA}$. In-situ X-ray diffraction (XRD) measurements were done by means of PANalytical's Empyrean diffractometer using $\mathrm{Cu} \mathrm{K} \alpha(\lambda=1.5418 \AA)$ equipped with the Anton Paar's HTK1200 high-temperature chamber in the temperature

Table I. Heating Parameters for the Applied Techniques

\begin{tabular}{llc}
\hline Technique & $\begin{array}{c}\text { Measurement } \\
\text { Type }\end{array}$ & $\begin{array}{c}\text { Averaged Heating } \\
\text { Rate }(\mathrm{K} / \mathrm{min})\end{array}$ \\
\hline XRD & static & 0.15 \\
VSM & static & 0.6 \\
Dilatometry & quasi static & 3 \\
DSC & quasi static & 20 \\
\hline
\end{tabular}


range of $273 \mathrm{~K}$ to $973 \mathrm{~K}\left(0{ }^{\circ} \mathrm{C}\right.$ to $\left.700{ }^{\circ} \mathrm{C}\right)$. During the experiment, the sample was maintained under vacuum conditions (pressure lower than $6 \times 10^{-7} \mathrm{mbar}$ ). The sample's position was corrected with respect to temperature displacements during the measurements (tungsten powder of 99.9999 pct purity was used as a standard). The temperature step was set at $323 \mathrm{~K}\left(50{ }^{\circ} \mathrm{C}\right)$, where each temperature was approached by a ramp of $10 \mathrm{~K} /$ min, then the sample's temperature was stabilized for 20 minutes. Afterwards, diffraction patterns were collected in the range of 30 to $85 \mathrm{deg}$ for the $2 \Theta$ angles. The single diffraction pattern's acquiring time was 4:30 hours. The obtained data were analyzed using the Rietveld-type FullProf Suite package.

\section{RESULTS}

\section{A. Formation of Strain-Induced Martensite}

Basic mechanical properties of the materials at various temperatures were obtained in the tensile test. Additionally, hardness measurements were performed on the fractured specimens. True stress-strain curves are shown in Figure 1(a). A typical increase of stress is visible on samples tested in low temperatures. This phenomenon corresponds to the SIM formation. ${ }^{[2,3]}$

A clear influence of deformation temperature on elongation as well as UTS (ultimate tensile strength) is observed. For comparison purposes, data of hardness, elongation, UTS with respect to deformation temperature are presented in Figure 2. Among the presented parameters, only UTS exhibits linear behavior within the tested temperature range with regression coefficient of $-5.3 \mathrm{MPa} / \mathrm{K}$, while the elongation and hardness show non-linear behavior. At $263 \mathrm{~K}\left(-10^{\circ} \mathrm{C}\right)$ maximum elongation is reported. Both the increase and the decrease of the temperature lead to the reduction of elongation. Such behavior corresponds very well to the results obtained by other authors ${ }^{[32]}$; however, different values of the maximum elongation temperature were

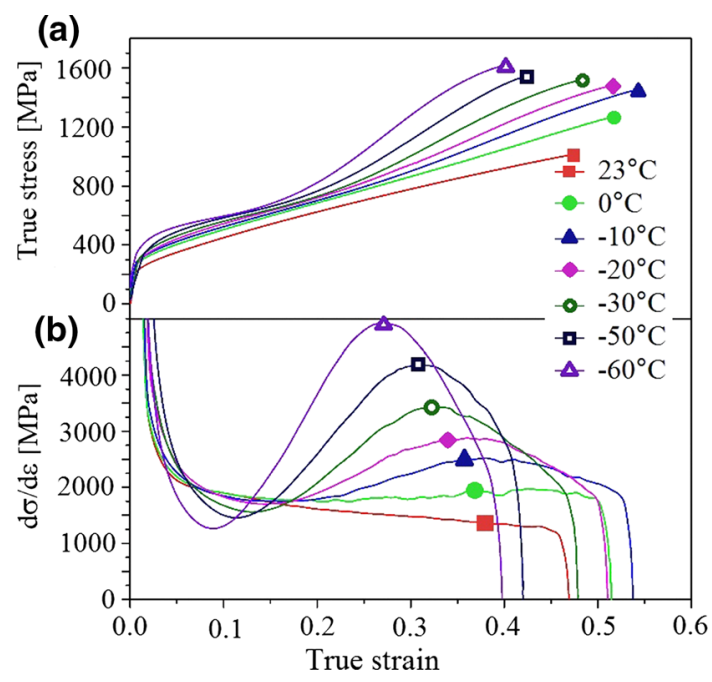

Fig. 1-Stress-strain curves (a) and work hardening plot $(b)$ for AISI 304 stainless steel. observed. The characteristic temperature of $263 \mathrm{~K}$ $\left(-10^{\circ} \mathrm{C}\right)$ is also reported for hardness measurements. It can be seen in Figure 2 that this particular temperature point is connected with the change of the hardness evolution rate. The hardness of the sample deformed at $296 \mathrm{~K}\left(23{ }^{\circ} \mathrm{C}\right)(340 \mathrm{HV} 1)$ doubled in comparison to the solution heat-treated sample (156 HV1). Moreover, the hardness of the sample deformed at $213 \mathrm{~K}\left(-60{ }^{\circ} \mathrm{C}\right)$ (459 HV1) was three times higher than that of the sample in solution heat-treated state which is caused by strain hardening and the formation of SIM.

In order to elucidate the work hardening change during the tensile experiment, derivatives $\mathrm{d} \sigma / \mathrm{d} \varepsilon$ were calculated (Figure 1(b)). The curves exhibit two characteristic features: the so-called "softening" effect at low strains and work hardening effect at strains above 0.2. Both aspects are well-known features of metastable stainless steel materials related to the kinetics of $\gamma \rightarrow \varepsilon$ and $\varepsilon \rightarrow \alpha^{\prime}$ transformations. ${ }^{[3]}$

It is assumed that the maximum of the reaction rate $(\varepsilon$ and $\alpha^{\prime}$ phase formation, respectively) occurs at the derivative extrema. ${ }^{[3]}$ As the temperature drops, both extrema are shifted toward lower strains (Figure 3) and this phenomenon follows a linear relationship with respect to deformation temperature.

The microstructures of solution heat treated and deformed at RT and $223 \mathrm{~K}\left(-50{ }^{\circ} \mathrm{C}\right)$ samples are shown in Figure 4. The heat-treated sample exhibits a typical single-phase AISI 304 microstructure with equiaxial grains and annealing twins. It is important to notice that due to the application of initial thermal treatment procedure neither carbides nor strain-induced martensites were present in the microstructure prior to deformation. The material deformed at RT shows a

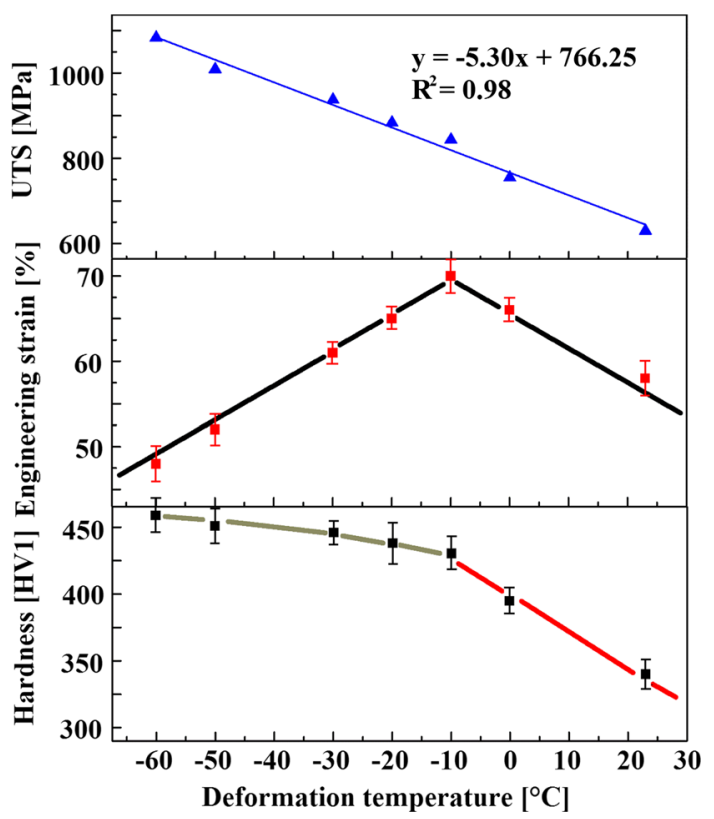

Fig. 2-The influence of the deformation temperature on UTS elongation and hardness in the uniform plastic deformation zone (hardness in solution heat-treated sample was $156 \mathrm{HV}$ 1) of AISI 304 stainless steel (lines are only guides for your eyes, error bars for UTS are not bigger than $20 \mathrm{MPa}$ ). 
microstructure with typical shear bands and martensite features $^{[4]}$ (Figure 4(b)). The decrease of the deformation temperature leads to the intensification of this phenomenon as can be seen in Figure 4(c). Additionally, the microstructure of the shear bands is substantially refined with respect to the room temperature in the deformed sample.

In order to obtain qualitative information about the phases present in the deformed microstructure, XRD analysis was performed (Figure 5). The solution heattreated sample shows only $\gamma$ phases while characteristic peaks of $\alpha^{\prime}$ martensite are additionally visible in the deformed samples. Increasing peak intensities of BCC phase with a decrease of deformation temperature can also be seen. No $\varepsilon$ phase was revealed in any of the samples.

\section{B. Reverse Transformation of the Strain-Induced Martensite}

In order to investigate the reverse transformation of SIM, a multi-method approach was applied. Three different in-situ methods: DSC, dilatometry, and VSM were used to elucidate the start and finish temperatures of the transformation and to show its kinetics. For the material deformed at $243 \mathrm{~K}\left(-30^{\circ} \mathrm{C}\right)$, in-situ X-ray analysis was performed during the heating experiment. The same sample was also subjected to isothermal annealing at temperatures of $873 \mathrm{~K}, 973 \mathrm{~K}$, and $1073 \mathrm{~K}$

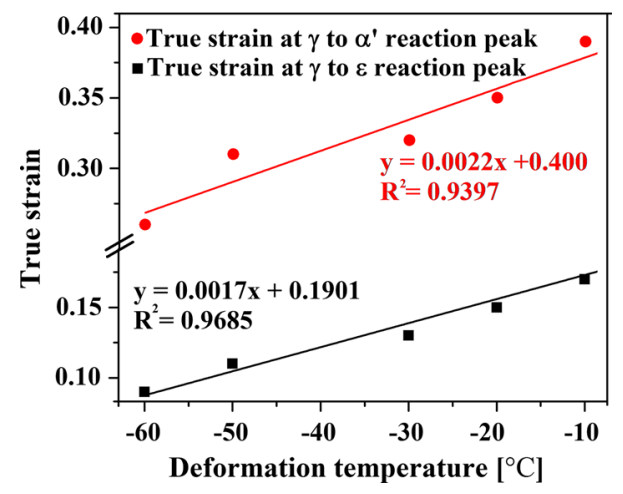

Fig. 3-True strain at the maximum reaction rates of $\gamma \rightarrow \alpha^{\prime}$ and $\gamma \rightarrow \varepsilon v s$ deformation temperature. $\left(600{ }^{\circ} \mathrm{C}, 700{ }^{\circ} \mathrm{C}\right.$, and $800{ }^{\circ} \mathrm{C}$ ) (soaking time 4 hours) and investigated by means of TKD technique.

The results of the DSC experiments are presented in Figure 6. The curves obtained for samples deformed at temperatures of $273 \mathrm{~K}\left(0^{\circ} \mathrm{C}\right)$ and below show an endothermic effect related to the martensite-to-austenite transformation. The reaction start temperature was about $723 \mathrm{~K}\left(450{ }^{\circ} \mathrm{C}\right)$; however, it was not possible to estimate the finish temperature. In case of the specimens deformed below $263 \mathrm{~K}\left(-10{ }^{\circ} \mathrm{C}\right)$, an additional effect was observed, i.e., a small exothermic peak at about $823 \mathrm{~K}\left(550{ }^{\circ} \mathrm{C}\right)$ was also found.

A thorough microstructure investigation allowed us to put a hypothesis that this effect is related to the internal strain relaxation. A detailed description and discussion is presented further in this study.

Dilatometric curves acquired during heating as well as their derivatives are presented in Figure 7. A significant sample shrinkage effect was observed between $723 \mathrm{~K}$

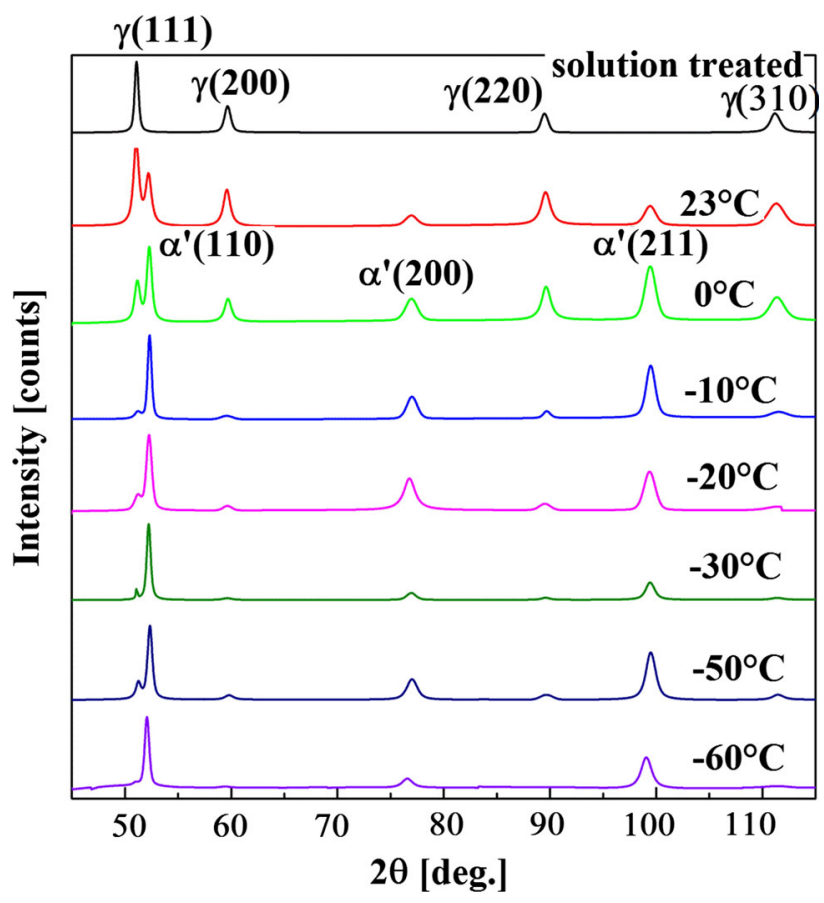

Fig. 5-XRD patterns of solution heat-treated and deformed AISI 304 stainless steel, the intensity is given in square root scale. (a)

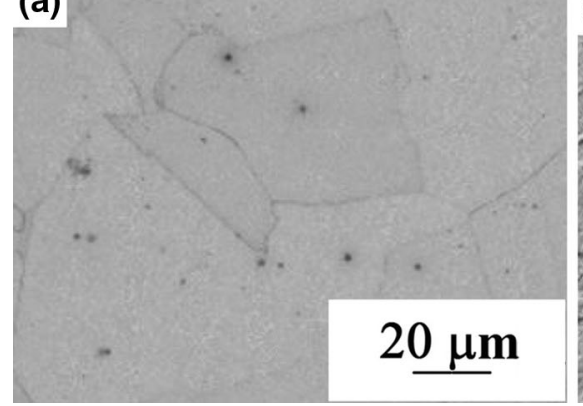

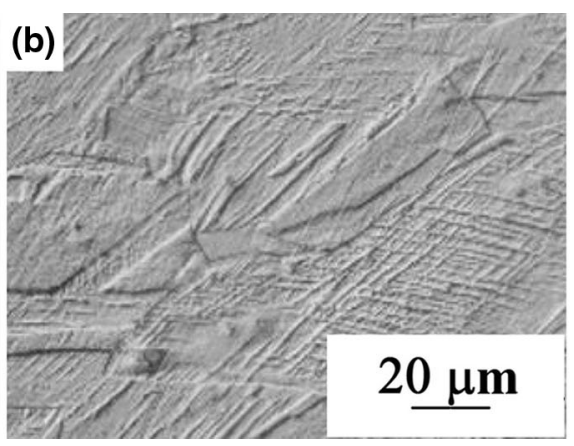

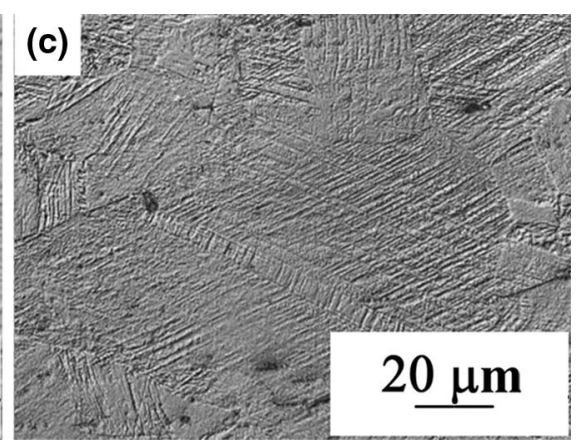

Fig. 4-Microstructure of AISI 304 stainless steel $(a)$ solution heat treated (BF), (b) deformed at $296 \mathrm{~K}\left(23{ }^{\circ} \mathrm{C}\right.$, uniform elongation of 57 pct) (DIC), (c) deformed at $223 \mathrm{~K}\left(-50^{\circ} \mathrm{C}\right.$, uniform elongation of $\left.51 \mathrm{pct}\right)$ (DIC). 
and $1113 \mathrm{~K}\left(450{ }^{\circ} \mathrm{C}\right.$ and $\left.840{ }^{\circ} \mathrm{C}\right)$. Based on the differential curves, two distinct stages can be distinguished in the above-mentioned temperature range. The first substantial drop ranging from $723 \mathrm{~K}$ to $923 \mathrm{~K}\left(450{ }^{\circ} \mathrm{C}\right.$ to $700{ }^{\circ} \mathrm{C}$ ) (Stage 1) can be attributed to the SIM reverse transformation, while the second one, much less pronounced, ranging from $923 \mathrm{~K}$ to $1113 \mathrm{~K}\left(700{ }^{\circ} \mathrm{C}\right.$ to $840{ }^{\circ} \mathrm{C}$ ) (Stage 2), is most probably related to recrystallization and carbides precipitation. Similarly to the DSC experiment, a characteristic feature in the curve flow is also observed at a temperature of about $823 \mathrm{~K}\left(550{ }^{\circ} \mathrm{C}\right)$ (marked by arrow in Figure 7(b)). Assuming that the change rate of the differential curve is coupled with the kinetics of the martensite-austenite transformation, a slowdown of reaction at the given temperature is observed. Martensite to austenite start and finish

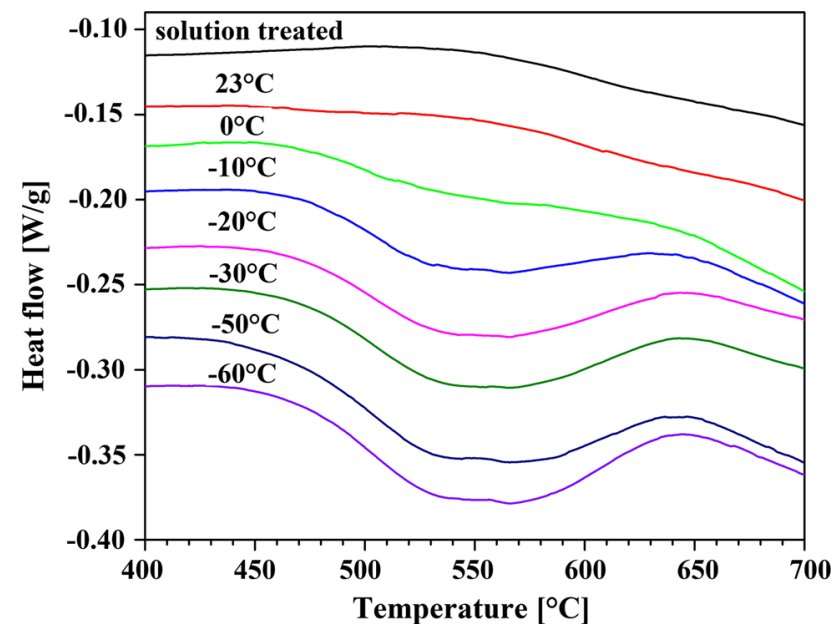

Fig. 6-DSC of deformed AISI 304 stainless steel.

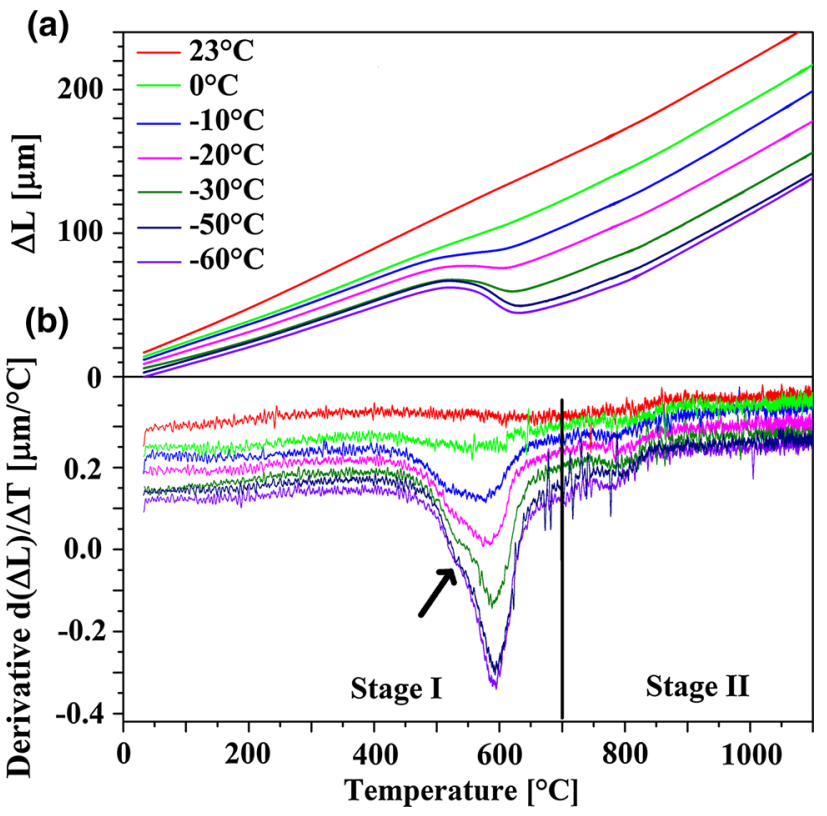

Fig. 7-Dilatometric curves of heating (a) their differential curves $(b)$ of deformed AISI 304 stainless steel. temperatures were found to be $723 \mathrm{~K}$ and $973 \mathrm{~K}$ $\left(450^{\circ} \mathrm{C}\right.$ and $\left.700{ }^{\circ} \mathrm{C}\right)$, respectively.

Figure 8 shows a change of magnetic properties during the in-situ heating experiment for fractured specimens. Up to $673 \mathrm{~K}\left(400{ }^{\circ} \mathrm{C}\right)$, a typical linear drop of magnetization value is visible and the first deviation from linearity is observed at the $\sim 693 \mathrm{~K}\left(\sim 420{ }^{\circ} \mathrm{C}\right)$ temperature range which determines the beginning of the reverse SIM transformation process. A substantial drop in magnetization above this point is related to the declining amount of martensite which is deplenished at $973 \mathrm{~K}\left(700{ }^{\circ} \mathrm{C}\right)$. Similarly to previous cases, derivative curves reveal a substantial change in the transformation kinetics at about $848 \mathrm{~K}\left(575{ }^{\circ} \mathrm{C}\right)$ (Figure $\left.8(\mathrm{~b})\right)$. Based on other researchers' assumption, volume fraction of SIM can be obtained by the division of specific magnetic saturation by $154 \mathrm{emu} / \mathrm{g}$ which is magnetization saturation of fully ferromagnetic AISI 304 material. ${ }^{[32]}$ This approximation is valid for the room temperature measurement only. The calculated values for the fractured samples are presented in Table II.

In order to explain microstructural changes during the reverse transformation, in-situ heating XRD experiments were performed on the sample deformed at $243 \mathrm{~K}\left(-30^{\circ} \mathrm{C}\right)$. The evolution of the diffraction peaks during the thermal cycle is presented at Figure 9(b). The rise of the (111) peaks at about $673 \mathrm{~K}\left(400{ }^{\circ} \mathrm{C}\right)$ and drop of $(110)_{\alpha}$, peaks intensity at about $873 \mathrm{~K}$ $\left(600{ }^{\circ} \mathrm{C}\right)$ can be clearly seen. The characteristic points correspond to the beginning and finish transformation temperatures, respectively, and correlate to the results gathered by other techniques. Based on the peaks' shifts, the lattice parameter of both $\alpha^{\prime}$ and $\gamma$ during heating, cycle phases were calculated. Thermal expansion gives a typical increase in the lattice parameter; however, at a temperature of $673 \mathrm{~K} \quad\left(400{ }^{\circ} \mathrm{C}\right)$ a significant abnormality is observed (Figure $9(\mathrm{~b})$ ). It is important to notice that this phenomenon is present in both martensite and austenite phases. Two additional curves obtained during the cooling of the reverse transformed sample and heating of the solution heat-treated sample are shown in Figure 9(a). In both mentioned cases, the curves are very similar without any abnormalities in the thermal expansion. This particular phenomenon at lattice parameter deviation corresponds to the beginning of the reverse transformation. It is suspected that this phenomenon is related to the relief of residual elastic strain acquired during the deformation process and SIM creation. After the reverse transformation has taken place, the stress is relieved and the material exhibits a typical thermal expansion behavior.

\section{Reverse Transformation Sequence-Microstructure Investigations}

The reverse SIM transformation is completed in temperatures of about $923 \mathrm{~K}\left(700{ }^{\circ} \mathrm{C}\right.$ ) (Figure 9(a)); however, an additional effect can be seen on the dilatometric curves up to $1123 \mathrm{~K}\left(850^{\circ} \mathrm{C}\right)$. In order to elucidate microstructural evolution, isothermal annealing of the as-deformed in $243 \mathrm{~K}\left(-30^{\circ} \mathrm{C}\right)$ specimen was 


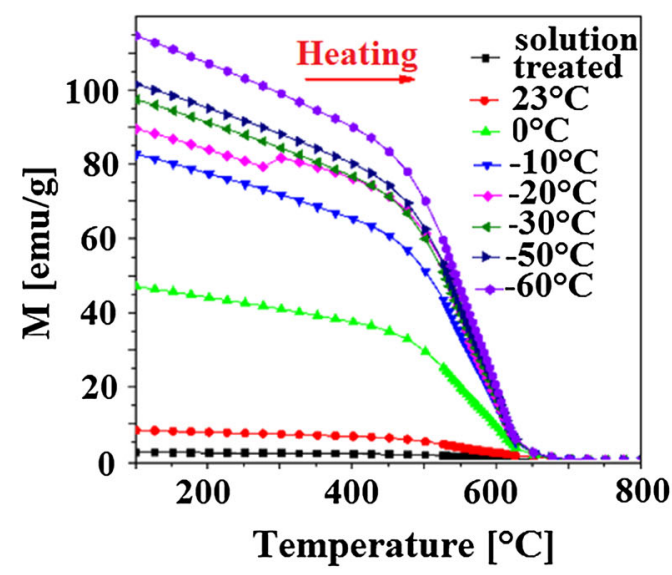

(a)

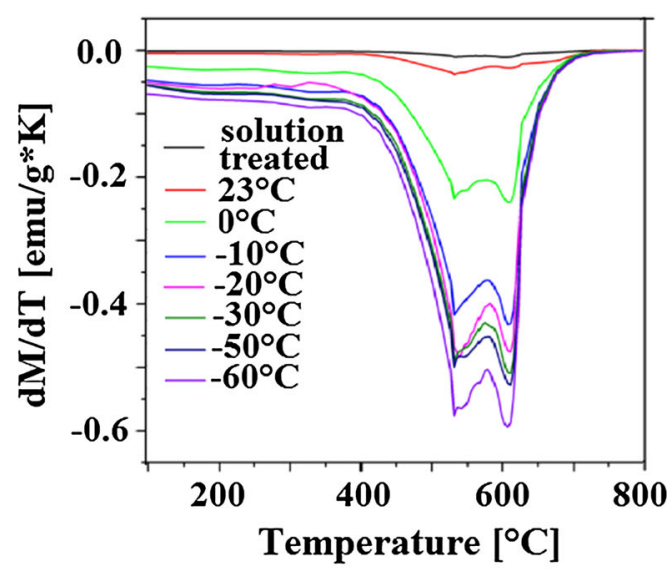

(b)

Fig. 8-(a) Magnetization $v s$ temperature during heating (magnetic field 1T), (b) derivative of magnetization $v s$ temperature during heating.

Table II. The Magnetic Saturation and Volume Fraction of $\alpha^{\prime}$ Martensite in Deformed AISI 304 Stainless Steel Before Heating up to $1103 \mathrm{~K}\left(830^{\circ} \mathrm{C}\right)$ and After the Cooling Process

\begin{tabular}{|c|c|c|c|c|c|c|c|c|}
\hline $\begin{array}{l}\text { Deformation } \\
\text { Temperature }\left({ }^{\circ} \mathrm{C}\right)\end{array}$ & $\begin{array}{l}\text { Solution Heat } \\
\text { Treated }\end{array}$ & $\begin{array}{c}296 \mathrm{~K} \\
\left(23^{\circ} \mathrm{C}\right)\end{array}$ & $\begin{array}{l}273 \mathrm{~K} \\
\left(0^{\circ} \mathrm{C}\right)\end{array}$ & $\begin{array}{c}263 \mathrm{~K} \\
\left(-10^{\circ} \mathrm{C}\right)\end{array}$ & $\begin{array}{c}253 \mathrm{~K} \\
\left(-20{ }^{\circ} \mathrm{C}\right)\end{array}$ & $\begin{array}{c}243 \mathrm{~K} \\
\left(-30{ }^{\circ} \mathrm{C}\right)\end{array}$ & $\begin{array}{c}223 \mathrm{~K} \\
\left(-50^{\circ} \mathrm{C}\right)\end{array}$ & $\begin{array}{c}213 \mathrm{~K} \\
\left(-60^{\circ} \mathrm{C}\right)\end{array}$ \\
\hline $\begin{array}{l}\text { Magnetization } \\
\text { saturation }(\mathrm{emu} / \mathrm{g})\end{array}$ & $2.56^{*}$ & 8.72 & 49.03 & 85.51 & 93.15 & 99.74 & 105.57 & 120.98 \\
\hline $\begin{array}{l}\text { Volume percent of } \\
\alpha^{\prime} \text { martensite }(\mathrm{pct})\end{array}$ & - & 5.44 & 30.57 & 53.31 & 58.08 & 62.19 & 65.82 & 75.43 \\
\hline
\end{tabular}

* Magnetic saturation of austenite and/or some amount of delta ferrite; however, delta ferrite was not found using other techniques.

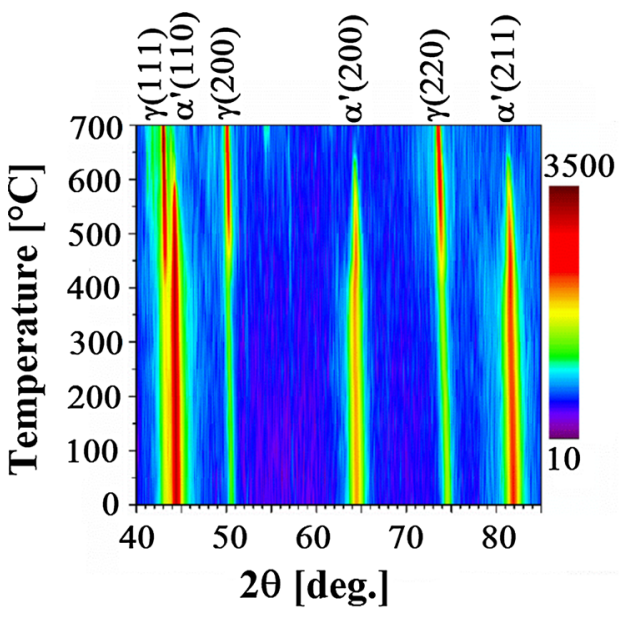

(a)

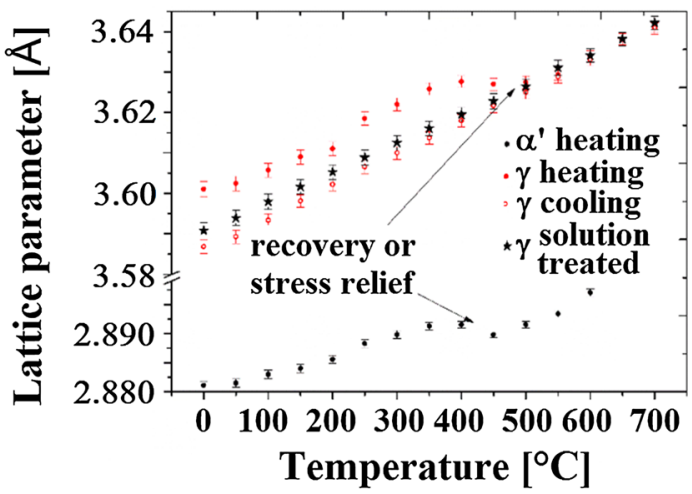

(b)

Fig. 9-Thermal evolution of the XRD diffraction pattern for AISI 304 stainless steel deformed at $243 \mathrm{~K}\left(-30{ }^{\circ} \mathrm{C}\right)(a)$ and lattice parameter of austenite and martensite in AISI 304 deformed at $243 \mathrm{~K}\left(-30^{\circ} \mathrm{C}\right)$ and the solution heat-treated sample $(b)$.

employed. Selected annealing temperatures of 873,973 , and $1073 \mathrm{~K}\left(600{ }^{\circ} \mathrm{C}, 700{ }^{\circ} \mathrm{C}\right.$, and $\left.800{ }^{\circ} \mathrm{C}\right)$ were chosen and correspond to characteristic features of stages I and II (Figure 7). The application of TKD technique allowed for clear identification of $\alpha^{\prime}$ and $\gamma$ phase distribution and crystallographic relationships. The data are presented in the form of PM (Phase Maps) and IPF (Inverse Pole Figures) maps. Additionally, Image
Quality maps (IQ) are included as separate images to show qualitative information about grain boundary distribution in the microstructure.

Figures 10(a) through (c) present a typical microstructure of the cold deformed sample. It can be seen that micro-shear bands confined within separate former austenitic grains are a major feature of the microstructure. The phase map reveals that a massive 


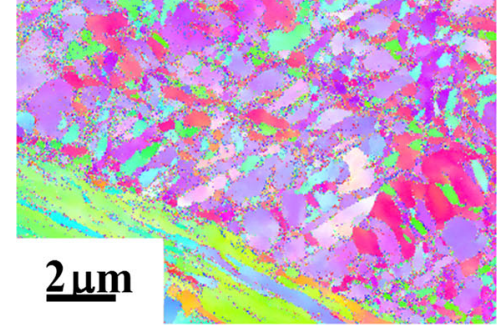

(a)

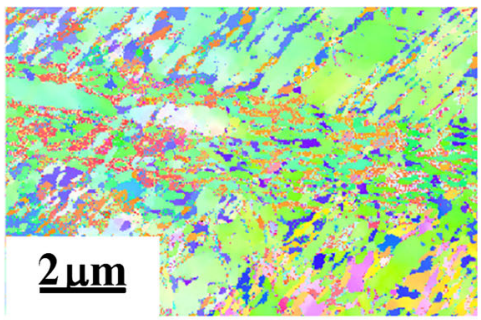

(d)

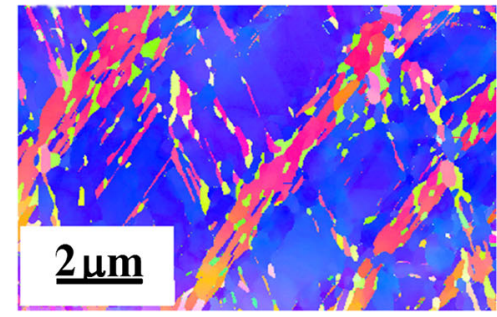

(g)

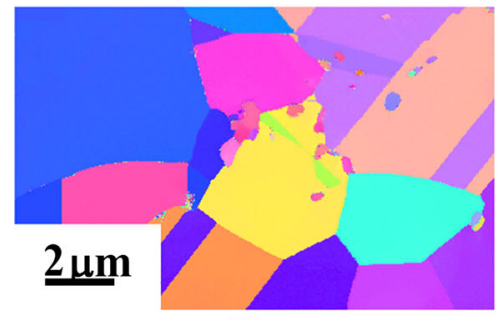

(j)

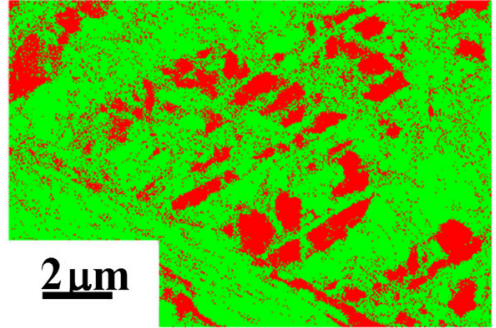

(b)

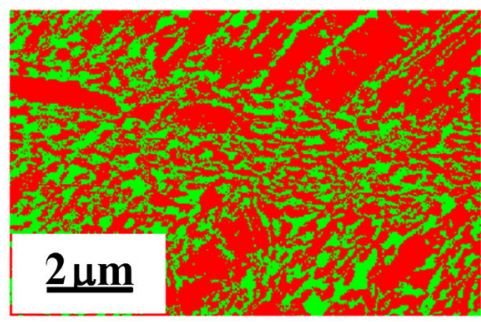

(e)

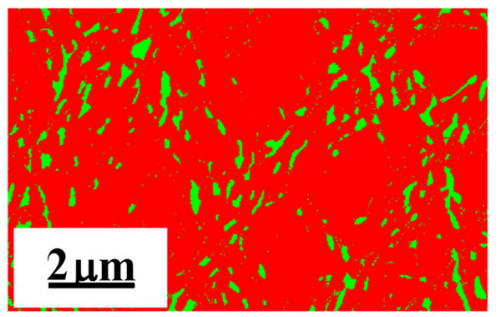

(h)

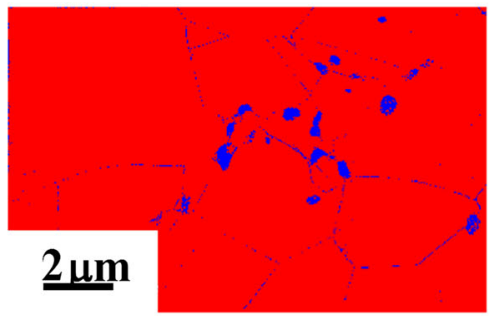

(k)

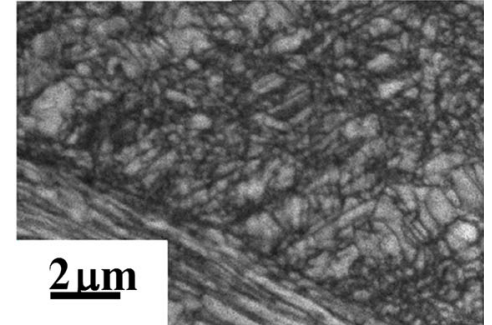

(c)

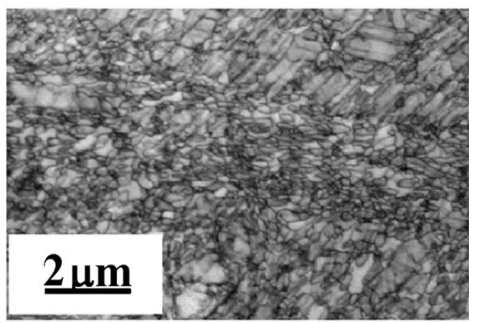

(f)

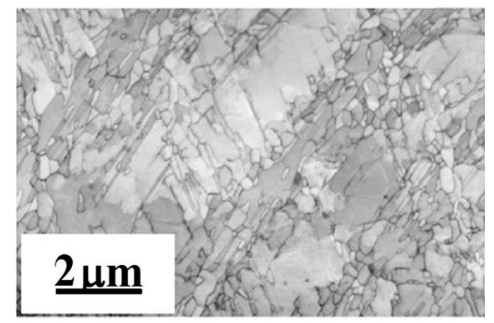

(i)

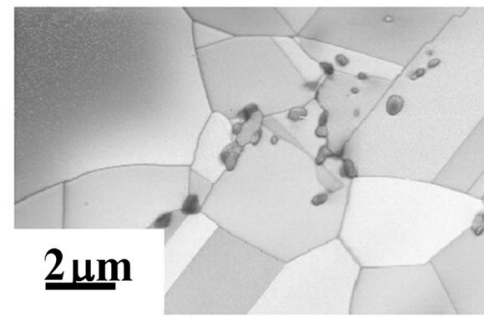

(I)

Fig. 10-TKD phase maps and corresponding orientation and IQ maps of deformed at $243 \mathrm{~K}\left(-30{ }^{\circ} \mathrm{C}\right)(a-c)$ and annealed at $873 \mathrm{~K}\left(600{ }^{\circ} \mathrm{C}\right)$ $(d-f), 973 \mathrm{~K}\left(700^{\circ} \mathrm{C}\right)(g-i)$, and $1073 \mathrm{~K}\left(800^{\circ} \mathrm{C}\right)(j-l)$ AISI 304 stainless steel, phase colors: green-SIM, red-austenite, blue- $\mathrm{M}_{23} \mathrm{C}_{6}(\mathrm{Color}$ figure online).

fraction of the material was transformed into the strain-induced martensite. Isothermal annealing at $873 \mathrm{~K} \quad\left(600^{\circ} \mathrm{C}\right)$ causes substantial microstructure change (Figures 10(d) through (f)). The reverse SIM transformation is active, leading to the formation of the austenite phase at average dimensions of approx. $50 \mathrm{~nm}$. Inside the austenite regions, due to recovery processes, dislocations are forming small-angle boundaries. Both mechanisms lead to considerable microstructure refinement (Figure 10(e)), which suggests a diffusionless reverse transformation mechanism. As the annealing temperature is increased up to $973 \mathrm{~K}\left(700{ }^{\circ} \mathrm{C}\right)$, which corresponds to the end of the reverse transformation process, most of the microstructure is transformed back to austenitic phase. Some martensite remnants arranged according to the shape of former shear bands are still present. It is also characteristic that a similar arrangement can be seen in the austenitic phase where two distinctive orientations can be seen on the IPF map: large areas surrounded by differently oriented elongated regions. Recovery processes are much more pronounced at $973 \mathrm{~K}\left(700^{\circ} \mathrm{C}\right)$, which leads to the dislocation rearrangement and coalescence of small sub-grains (Figure 10(i)). Figures 10(j) through (1) presents a typical microstructure of material annealed at $1073 \mathrm{~K}$ $\left(800^{\circ} \mathrm{C}\right)$. Large grains and annealing twins are present in the microstructure, which is an evidence of material recrystallization. Other microstructure features are precipitation during heat treatment and $\mathrm{M}_{23} \mathrm{C}_{6}$ carbides identified by means of TKD. In Figure 11 IPF, phase and IQ maps (a, b, c, respectively) are presented for the sample deformed at $243 \mathrm{~K}\left(-30^{\circ} \mathrm{C}\right)$ and annealed at 
$873 \mathrm{~K}\left(600^{\circ} \mathrm{C}\right)$. Additionally, local pole figures of neighboring SIM and reverted austenite were generated (Figure 11(d)). On the basis of local pole figures presented in Figure 11(d), the Kurdjumov-Sachs $(111)_{\gamma}||(110)_{\text {SIM }}$ and $[110]_{\gamma} \|[111]_{\text {SIM }}$ crystallographic orientation relationship was found.

\section{DISCUSSION}

The deformation behavior of the 304 alloy is governed by the combined effect of strain hardening of the austenitic phase and formation of the strain-induced martensite. The latter phenomenon depends on the deformation temperature and, as it drops, SIM formation is greatly intensified. The increased SIM formation kinetics during the temperature decrease can be observed on the derivative curves based on the peak height increase as well as the peak shift toward lower values of strain. Interestingly, the peak position is linearly dependent on the deformation temperature (Figure 3).

It is well known that the amount of martensite formed during deformation has significant impact on the specimen elongation. In the investigated case, the highest elongation is observed for the specimen deformed at $263 \mathrm{~K}\left(-10^{\circ} \mathrm{C}\right)$ when the total volume fraction of SIM for fractured specimens is about 50 pct. It is a typical TRIP (Transformation-Induced Plasticity) effect, where the creation of the hard martensitic phase causes the increase of the work hardening rate at a higher strain and enhanced ductility. ${ }^{[2,3]}$ However, at temperatures lower than $253 \mathrm{~K}\left(-20^{\circ} \mathrm{C}\right)$, the SIM formation rate is high enough to cause substantial reduction of ductile austenitic regions of materials at the early stages of deformation, thus an elongation decrease is observed. Similarly, hardness change exhibits a characteristic point at $263 \mathrm{~K}\left(-10{ }^{\circ} \mathrm{C}\right)$ when a change in the curve slope is observed. By plotting hardness change $v s$ volume of SIM for fractured specimens, linear dependency was found (Figure 12(b)). Taking the above into account, it was found that the temperature of $263 \mathrm{~K}$ $\left(-10^{\circ} \mathrm{C}\right)$ is the point where a change the kinetics of martensite formation is observed-below this given point the rise in the martensite volume fraction for fractured specimens is significantly less. Extrapolating hardness $v s$ the SIM fraction curve, hardness of the deformed austenite as well as martensite phase can be estimated. The values of $336 \mathrm{HV}$ and $510 \mathrm{HV}$ were found for the deformed austenite and martensite, respectively. Figure 12(a) presents TEC (Thermal Expansion Coefficient) calculated for different temperature ranges, namely, $303 \mathrm{~K}$ to $373 \mathrm{~K}\left(30{ }^{\circ} \mathrm{C}\right.$ to $\left.100{ }^{\circ} \mathrm{C}\right)$, $573 \mathrm{~K}$ to $673 \mathrm{~K}\left(300{ }^{\circ} \mathrm{C}\right.$ to $\left.400{ }^{\circ} \mathrm{C}\right)$, and $1173 \mathrm{~K}$ to $1273 \mathrm{~K}\left(900{ }^{\circ} \mathrm{C}\right.$ to $\left.1000{ }^{\circ} \mathrm{C}\right)$. Similarly to the hardness change linear behavior between TEC and SIM volume fraction is observed in temperatures below $673 \mathrm{~K}$ $\left(400{ }^{\circ} \mathrm{C}\right)$ (beginning of SIM reverse transformation) (Figure 12(a)). Typically, an increase in the amount of strain-induced martensite causes a decrease of thermal expansion coefficient and by extrapolation of the curves,

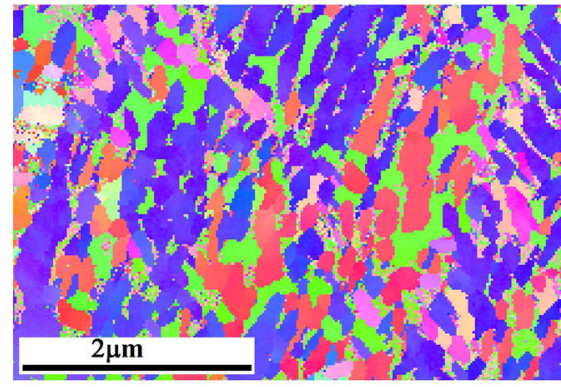

(a)

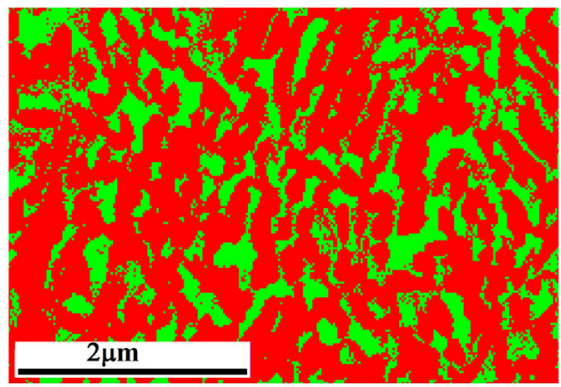

(b)

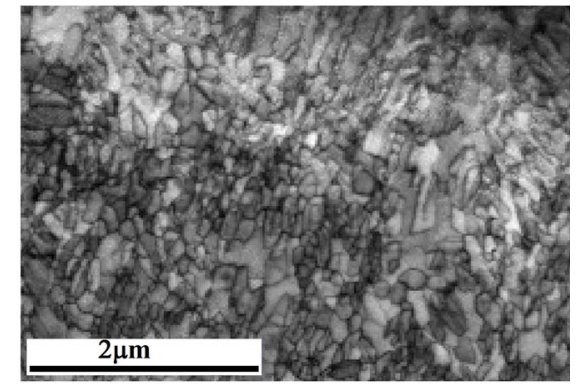

(c)

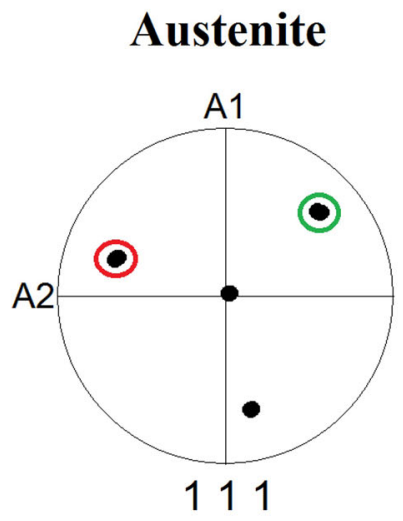

(d)

Fig. 11-TKD maps: IPF (a), phase (b), IQ (c), and local pole figures of neighboring SIM and austenite $(d)$ of deformed at $243 \mathrm{~K}\left(-30{ }^{\circ} \mathrm{C}\right)$ and annealed at $873 \mathrm{~K}\left(600{ }^{\circ} \mathrm{C}\right)$ AISI 304 steel. Phase colors: green-SIM, red-austenite (Color figure online). 


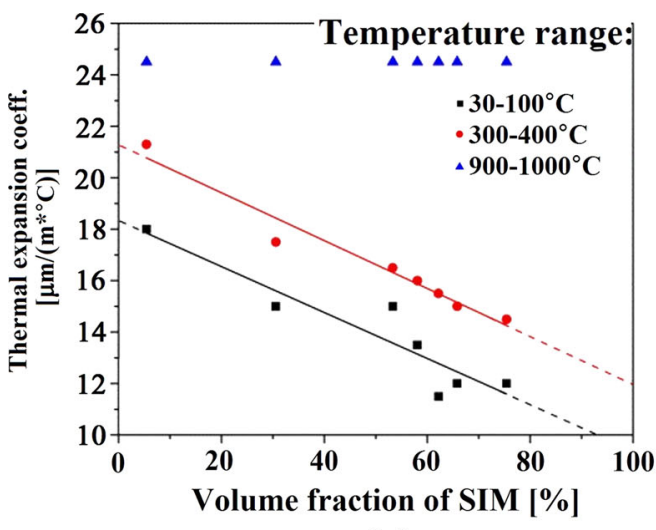

(a)

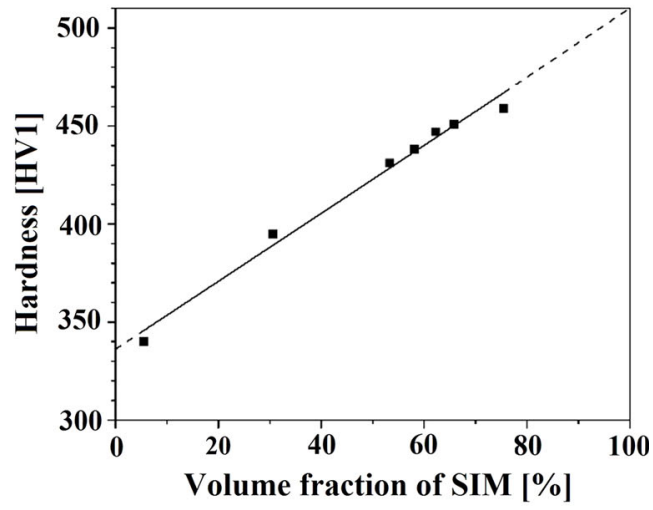

(b)

Fig. 12-The influence of volume fraction of strain-induced martensite on the thermal expansion coefficient $(a)$ and on the hardness of deformed AISI $304(b)$ (the thermal expansion coefficient in the range of $573 \mathrm{~K}$ to $673 \mathrm{~K}\left(300{ }^{\circ} \mathrm{C}\right.$ to $400{ }^{\circ} \mathrm{C}$ ) and $303 \mathrm{~K}$ to $373 \mathrm{~K}\left(30{ }^{\circ} \mathrm{C}\right.$ to $\left.100{ }^{\circ} \mathrm{C}\right)$ pos-

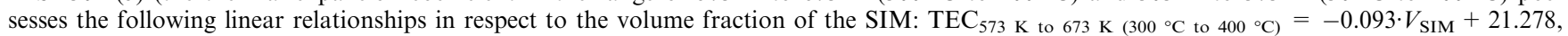
$\mathrm{TEC}_{303 \mathrm{~K} \text { to } 373 \mathrm{~K}\left(30^{\circ} \mathrm{C} \text { to } 100{ }^{\circ} \mathrm{C}\right)}=-0.0893 \cdot V_{\mathrm{SIM}}+18.334$; hardness possesses the following linear relationship in respect to the volume fraction of SIM: hardness $\left.[\mathrm{HV}]=1.7736 \cdot V_{\mathrm{SIM}}+336.1\right)$.

the TEC for the austenitic and martensitic phase can be calculated. It was found that the austenitic phase exhibits a TEC of 18.3 and $21.5 \mu \mathrm{m} /\left(\mathrm{m}{ }^{\circ} \mathrm{C}\right)$ for $303 \mathrm{~K}$ to $373 \mathrm{~K}\left(30{ }^{\circ} \mathrm{C}\right.$ to $\left.100{ }^{\circ} \mathrm{C}\right)$ and $573 \mathrm{~K}$ to $673 \mathrm{~K}\left(300{ }^{\circ} \mathrm{C}\right.$ to $400{ }^{\circ} \mathrm{C}$ ) range, respectively, where the martensitic phase shows 9 and $12.5 \mu \mathrm{m} /\left(\mathrm{m}{ }^{\circ} \mathrm{C}\right)$ in the corresponding temperature ranges.

High-temperature TEC $\left[1173 \mathrm{~K}\right.$ to $1273 \mathrm{~K}\left(900{ }^{\circ} \mathrm{C}\right.$ to $\left.\left.1000{ }^{\circ} \mathrm{C}\right)\right]$ has the same value of $25 \mu \mathrm{m} /\left(\mathrm{m}^{\circ} \mathrm{C}\right)$ for all samples as a result of a fully austenitic structure after a full reverse SIM transformation.

In-situ kinetics of the reverse SIM transformation was analyzed by four different measurement techniques: calorimetry, dilatometry, magnetometry, and X-ray diffraction. Temperatures of about $723 \mathrm{~K}$ and $973 \mathrm{~K}$ $\left(450{ }^{\circ} \mathrm{C}\right.$ and $\left.700{ }^{\circ} \mathrm{C}\right)$ were found for the start and finish temperatures of the reverse SIM transformation, respectively. It is important to mention that similar values were obtained for all the techniques despite one order of magnitude speed differences in heating speeds during measurements. It is the first sign for the diffusionless transformation type as the SIM transformation is independent of the time variable.

An additional effect was revealed during the reverse transformation by means of calorimetry, dilatometry, and magnetometry experiments around $823 \mathrm{~K}$ $\left(550{ }^{\circ} \mathrm{C}\right)$ where the kinetics of the reverse transformation is altered. Splitting is observed in all of the curves' peaks irrespectively of the amount of martensite present in the material microstructure. According to the authors' knowledge, no explanation of such an effect can be found in the literature. This "two-stage" process can be explained with the help of the in-situ XRD experiment. The lattice parameter change (Figure 9(b)) shows substantial deviation from linearity in both austenitic and martensitic phase at the temperature of $673 \mathrm{~K}\left(400{ }^{\circ} \mathrm{C}\right)$ while at $773 \mathrm{~K}$ $\left(500{ }^{\circ} \mathrm{C}\right)$, the lattice expansion follows a linear curve during cooling caused by thermal expansion. The beginning of this phenomenon corresponds to the start of the SIM reversal transformation.
It is proposed that for the given region of temperatures, significant release of residual strains is observed. Those strains inherited from the deformation process or created by different expansion coefficient of austenitic and martensitic phases are the driving force for increased kinetics of the reverse transformation at the early stages of the process. After strains release, kinetics of transformation slows down and its further increase (second part of the peak) is related to temperature rise.

The microstructure TKD analysis confirms the above-mentioned results. In all of the investigated cases, the nucleation and growth of austenitic phases was not observed. Such behavior would create various orientations in separate regions of the reversed austenite and should signal a diffusive type of reversion transformation, according to Tomimura et al. ${ }^{[22]}$ Contrarily, all regions (reverted austenite within one grain) possess a similar orientation with some misorientation caused by the rearrangement of dislocations during the recovery process. Moreover, the Kurdjumov-Sachs crystallographic orientation relationship between SIM and reverted austenite was found (Figure 11). Based on Tomimura et al. widely accepted SIM reverse transformations definitions, we found diffusionless shear transformation. ${ }^{[22]}$ It is in contradiction to the work of Sun et al., ${ }^{[29]}$ where based on TEM analysis, the authors found that a similar alloy was transformed by a diffusion-type mechanism. Based on current knowledge, it is hard to find an explanation to this discrepancy as it can be a result of a slightly different chemical composition or materials' processing history. A detailed analyses of the Fe-Cr-Ni system and the SIM formation and reverse transformations are still needed.

\section{CONCLUSIONS}

1. Transformation-induced plasticity gave the highest increase of elongation at the temperature of $263 \mathrm{~K}$ $\left(-10{ }^{\circ} \mathrm{C}\right)$, where $\sim 50 \mathrm{pct}$ of the SIM was found after deformation. 
2. Maximum reaction rate of $\varepsilon$ and $\alpha^{\prime}$ formation was found to have a linear correlation to temperature; as temperature decreases maxima are shifted toward lower strains.

3. The amount of SIM increases with temperature decrease; the highest increase of SIM is observed up to the temperature of maximum elongation.

4. The reverse transformation of SIM takes place in the range of $723 \mathrm{~K}$ to $973 \mathrm{~K}\left(450{ }^{\circ} \mathrm{C}\right.$ to $\left.700{ }^{\circ} \mathrm{C}\right)$ and it is not dependent on the heating rate (in investigated range of heating rates).

5. The kinetics of the SIM reverse transformation reveals two distinct stages; in-situ XRD suggests that first stage can be stress assisted.

6. The Kurdjumov-Sachs crystallographic orientation relationship between SIM and reverted austenite was found.

7. On the basis of the microstructural TKD measurements, diffusionless (shear) reversion was found; shear reversion is in agreement with the theory of stress-assisted reversion of SIM.

\section{ACKNOWLEDGMENTS}

This research was supported by the Polish National Science Centre (NCN) under Project No. 2016/23/N/ ST8/01252.

\section{OPEN ACCESS}

This article is distributed under the terms of the Creative Commons Attribution 4.0 International License (http://creativecommons.org/licenses/by/4.0/), which permits unrestricted use, distribution, and reproduction in any medium, provided you give appropriate credit to the original author(s) and the source, provide a link to the Creative Commons license, and indicate if changes were made.

\section{REFERENCES}

1. G.B. Olson and M. Cohen: J. Less-Common Met., 1972, vol. 28, pp. 107-18.

2. T. Biggs and R.D. Knutsen: J. Phys. IV., 1995, vol. 5, pp. 515-20.
3. T.F.A. Santos and M.S. Andrade: Materia (Rio J.), 2008, vol. 13, pp. $587-96$.

4. S.S.M. Tavares, D. Gunderov, V. Stolyarov, and J.M. Neto: Mater. Sci. Eng. A., 2003, vol. 358, pp. 32-36.

5. S.M. Abbasi, A. Shokuhfar, N. Ehsani, and M. Morakabati: $J$. Metall., 2008, vol. 14, pp. 55-65.

6. J.-Y. Choi and W. Jin: Scr. Mater., 1997, vol. 36, pp. 99-104.

7. M.C. Young, J.Y. Huang, and R.C. Kuo: Mater. Trans., 2009, vol. 50, pp. 657-63.

8. S.M. Alvarez, A. Bautista, and F. Velasco: Corros. Sci., 2013, vol. 69 , pp. $130-38$

9. M.S. Andrade, O.A. Gomes, J.M.C. Vilela, A.T.L. Serrano, and J.M.D. de Moraes: J. Braz. Soc. Mech. Sci. Eng., 2004, vol. 26, pp. 47-50.

10. R. Makkouk, N. Bourgeois, J. Serri, B. Bolle, M. Martiny, and M. Teaca: Eur. J. Mech. A, 2008, vol. 27, pp. 181-94.

11. B.M. Gonzalez, C.S.B. Castro, V.T.L. Buono, J.M.C. Vilela, M.S. Andrade, and J.M.D. Moraes: Mater. Sci. Eng. A., 2003, vol. 343, pp. 51-56.

12. J.B.R. Lawrence: Master Thesis, Kingston, Ontario, 2010.

13. M. Martin, S. Weber, C. Izawa, S. Wagner, and A. Pundt: Int. J. Hydrog. Energy., 2011, vol. 36, pp. 11195-1206.

14. H. Cho and M. Takemoto: J. Acoust. Emiss., 2007, vol. 25, pp. $5-10$

15. M.J. Morgan, P. Lam, and D.A. Wheeler: 19th High Aver, Power Laser Progr. Work, Minerva, OH, USA, 2008.

16. J. Stolarz, N. Baffie, and T. Magnin: Mater. Sci. Eng. A., 2001, vols. 319-321, pp. 521-26.

17. B. Skoczeń: Int. J. Solids Struct., 2007, vol. 44, pp. 5182-5207.

18. E.S. Perdahcioglu and H.J.M. Geijselaers: Acta Mater., 2012, vol. 60 , pp. $4409-19$.

19. G. Ziętek and Z. Mróz: Int. J. Struct. Chang. Solids., 2011, vol. 3, pp. 21-34.

20. M.S. Simões, A.L.R. de Castro, and M.S. Andrade: Rev. Esc. Minas., 2010, vol. 63, pp. 051-55.

21. T.F.A. Santos, M.S. Andrade, and A.L.R. De Castro: Rev. Esc. Minas., 2009, vol. 62, pp. 53-58.

22. K. Tomimura, S. Takaki, and Y. Tokunaga: ISIJ Int., 1991, vol. 31 , pp. 1431-37.

23. A. Di Schino, I. Salvatori, and J.M. Kenny: J. Mater. Sci., 2002, vol. 37, pp. 4561-65.

24. R.D.K. Misra, S. Nayak, S.A. Mali, J.S. Shah, M.C. Somani, L.P. Karjalainen: Metall. Mater. Trans. A., 2009, vol. 41A, pp. $3-12$.

25. S. Rajasekhara, L.P. Karjalainen, A. Kyröläinen, and P.J. Ferreira: Mater. Sci. Eng. A., 2010, vol. 527, pp. 1986-96.

26. I. Shuro, M. Umemoto, Y. Todaka, and S. Yokoyama: Mater. Sci. Forum., 2010, vols. 654-656, pp. 334-37.

27. L. Zhu, A. Chen, and J. Lu: Theor. Appl. Mech. Lett., 2012, vol. 021001, pp. 1-9.

28. F. Forouzan, A. Najafizadeh, A. Kermanpur, and A. Hedayat: Int. J. ISSI., 2009, vol. 6, pp. 6-13.

29. A. Rezaee, A. Najafizadeh, A. Kermanpur, and M. Moallemi: Mater. Des., 2011, vol. 32, pp. 4437-42.

30. G.S. Sun, L.X. Du, J. Hu, H. Xie, H.Y. Wu, and R.D.K. Misra: Mater. Charact., 2015, vol. 110, pp. 228-35.

31. T. Tokarski, G. Cios, A. Kula, and P. Bała: Mater. Charact., 2016, vol. 121, pp. 231-36.

32. M.B. Stearns: Phys. Rev. B., 1976, vol. 13, pp. 1183-97. 